Article

\title{
Impedance Spectroscopy for the Characterization of the All-Carbon Graphene-Based Solar Cell
}

\author{
Ilaria Matacena ${ }^{1} \mathbb{C}$, Laura Lancellotti ${ }^{2}$, Nicola Lisi ${ }^{3}$, Paola Delli Veneri ${ }^{2}$, Pierluigi Guerriero ${ }^{1} \mathbb{1}$ \\ and Santolo Daliento ${ }^{1, *}$ \\ 1 Department Electrical Engineering and Information Technology, University Federico II, via Claudio 21, \\ 80125 Naples, Italy; ilaria.matacena@unina.it (I.M.); pierluigi.guerriero@unina.it (P.G.) \\ 2 ENEA, Portici Research Center, P. le E. Fermi 1, 80055 Portici, Naples, Italy; laura.lancellotti@enea.it (L.L.); \\ paola.delliveneri@enea.it (P.D.V.) \\ 3 ENEA, Casaccia Research Center, Via Anguillarese 301, 00060 Rome, Italy; nicola.lisi@enea.it \\ * Correspondence: daliento@unina.it; Tel.: +39-817683122
}

Received: 2 March 2020; Accepted: 8 April 2020; Published: 14 April 2020

\begin{abstract}
In this work, front contacts for graphene-based solar cells are made by means of colloidal graphite instead of gold. The performance is characterized by exploiting impedance spectroscopy and is compared to the standard gold contact technology. Impedance data are analysed through equivalent circuit representation in terms of lumped parameters, suitable to describe the complex impedance in the frequency range considered in the experiments. Using this approach, capacitance-voltage of the considered graphene-silicon solar cell is found and the barrier height forming at the graphene-silicon interface is extracted.
\end{abstract}

Keywords: impedance spectroscopy; graphene; solar cell; Nyquist plot; capacitancevoltage measurements

\section{Introduction}

Among the numerous applications of graphene, the Schottky junction, which forms when it is deposited on crystalline silicon, has been proposed as cost-effective solar cell [1], with graphene acting as the metal of a metal-semiconductor (MS) junction. As expected in MS solar cells, the overall behaviour of the device is strongly influenced by the behaviour of the interfaces existing in the considered device. One of such interfaces is formed by the metal contacts, which, on graphene, are usually made in gold. Having a deep insight into the phenomena taking place at those interfaces can give a better understand of the whole solar cell design. For this purpose, several characterization techniques have been studied with the aim of separating the contribution of each interface in the total solar cell behaviour [2-8]. The most used electrical characterization techniques are based on impedance measurement. As an example, it is possible to gain precise information by analysing the relationship between the capacitance and certain measurement parameters, such as the DC bias $(\mathrm{C}-\mathrm{V}$ plots) or the frequency of the test signal (C-f plots) [9]. On the other hand, the right explanation of these plots might be very arduous, and, sometimes, leading to inaccurate conclusions. As a matter of fact, the total impedance which is measurable by accessing the external terminals of the device under test (DUT), is the superposition of several physical phenomena coexisting in the device. Moreover, especially for high frequency measurements, parasitic contributions coming from the measurement circuit, may be erroneously attributed to the device [10]. Impedance data, in the form of Nyquist plots [11-13], can help to discern individual contribution to global behaviour. As it is widely known, these plots report the real part of the complex impedance on the x-axis and the imaginary part on the y-axis, taking frequency and DC bias as parameters. The resulting diagrams get very typical 
shapes, whose physical interpretation can be supported by searching for suitable equivalent circuits, with lumped elements (resistors, capacitors, inductors) associated to the phenomena taking place at each interface. The topology of such circuits can give strong indications about the role of active interfaces forming the device. As an example, it is known that a Nyquist plot with semicircular shape can be reproduced by a single (parallel) RC pair, with R given by the shunt resistance of the device and $\mathrm{C}$ (in the case of a solar cell) associated to the junction capacitance. The more the Nyquist plot differs from the semi-circular shape, the more several "active interfaces" are involved in the behaviour of the solar cell.

In this work, impedance spectroscopy, interpreted in terms of equivalent circuits, is adopted to characterize a new contact technology for graphene-based solar cells. This new technology exploits a graphitic glue to form the top contact, instead of gold. The performance of solar cells made by means of both above mentioned contacts are compared and interpreted in terms of effectiveness. The extracted circuit configurations for the two types of solar cells enabled us to isolate, from the global impedance, the contributions given by the Schottky interface (graphene-silicon interface) and that of contact-graphene interface (gold-graphene in one case, or glue-graphene in the other case) respectively. The knowledge of these contributions allowed us to extract the barrier height and the work function of the graphene-silicon interface and the contact resistance of the contact-graphene interface.

The paper is organized as follows: Section 2 contains an overview on the graphene-based solar cell processing; in Section 3 Nyquist plots are presented and measurement are described while in Section 4, the electrical properties of the solar cells are shown in terms of current-voltage (I-V) curves. Conclusions are drawn in Section 5.

\section{Solar Cells Processing}

Few layers of graphene (FLG) films were grown by chemical vapour deposition (CVD) of ethanol on $\mathrm{Cu}$ substrates at $1070{ }^{\circ} \mathrm{C}$. The details relative to the $\mathrm{CVD}$ growth based on ethanol vapor precursor, to the graphene transfer and to the steps involved in the fabrication of the $\mathrm{G} / \mathrm{n}-\mathrm{Si}$ cells have been previously reported by the authors [13-15].

The flow chart reported in Figure 1 resumes the cells fabrication process. The starting substrates were commercial n-type $\mathrm{Si}$ wafers, $1 \Omega \mathrm{cm}$, with a thermal $\mathrm{SiO}_{2}$ layer $(300 \mathrm{~nm})$ on both sides. The wafers were patterned through $\mathrm{HF}$ etching of $\mathrm{SiO}_{2}$, and an active area of $0.76 \mathrm{~cm}^{2}$ was obtained. The back contact was realized by evaporating $\mathrm{Al}$ on the back side of the wafer. The graphene films were transferred onto the cells by a cyclododecane (CD)-supported transfer [13]. Two kinds of top contacts were realized. The first was made by standard gold deposition by e-gun evaporation; the second was obtained through a colloidal graphitic glue, spread over the graphene outside the active area.

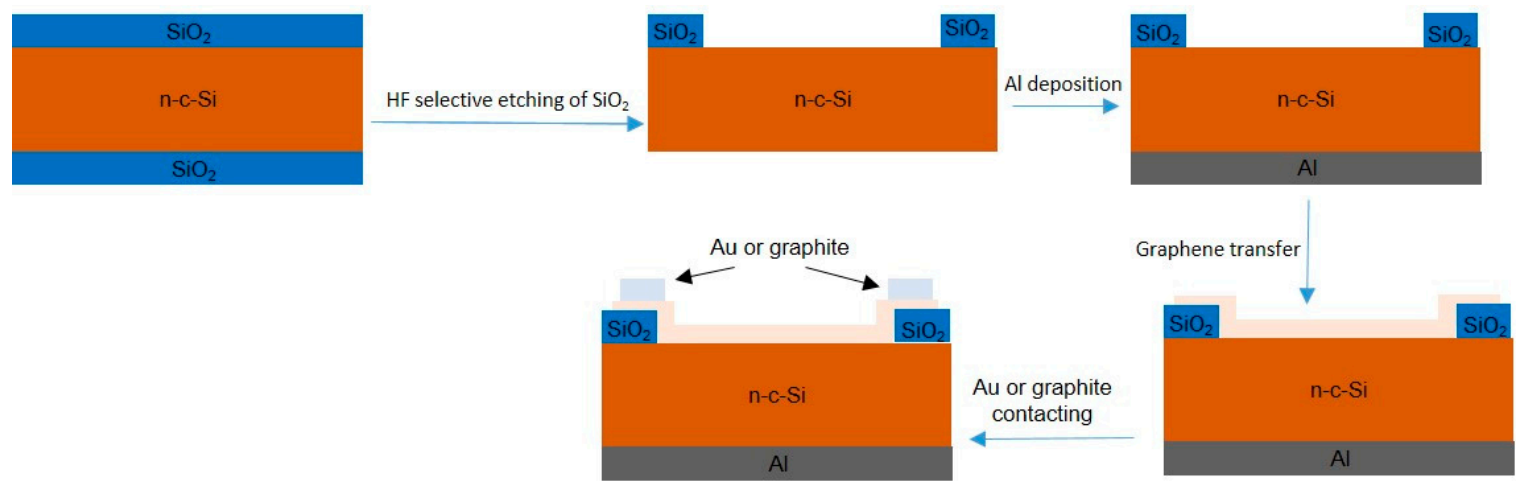

Figure 1. Schematic diagram of graphene-silicon $(\mathrm{G} / \mathrm{n}-\mathrm{Si})$ solar cell fabrication.

\section{Nyquist Plots and Circuit Representation}

Impedance representation in terms of Nyquist plots is made by reporting the real and imaginary parts of the measured impedance on the $\mathrm{x}$ - and $\mathrm{y}$-axis respectively. In these plots, each point is 
measured at a given frequency and each curve is given for a certain DC bias. Measurement setup used to collect impedance data consists in a 1260 Solartron Impedance Analyzer. The frequency was swept from $1 \mathrm{~Hz}$ to $63.5 \mathrm{kHz}$ with a logarithmic sweep, while DC bias was scanned from $-1 \mathrm{~V}$ to $0.5 \mathrm{~V}$. In Figure 2a, Nyquist plots for the solar cell with gold contact (Au/G/Si/Al) are shown. Looking at Figure 2a, it is clear that the Nyquist plots shapes are very different from the semicircular shape that should be observed if only the Schottky interface was dominating the AC behaviour. This means that the measured impedance is the results of the contribution of multiple reactive behaviours, rising from the various existing interfaces in the considered device.

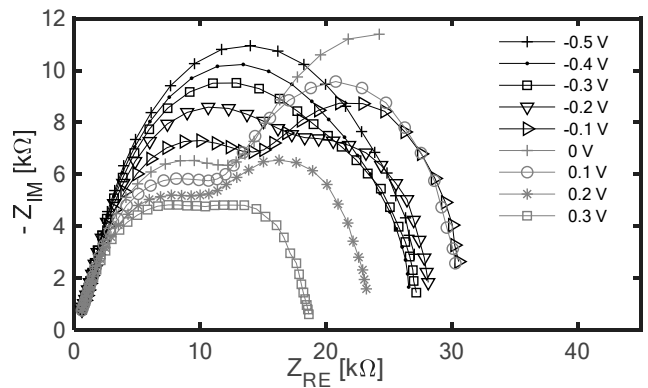

(a)

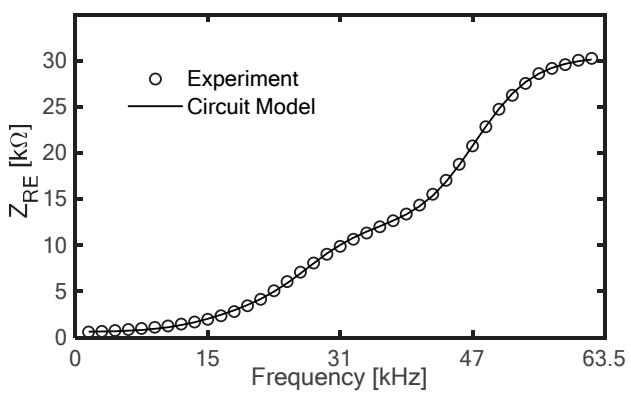

(c)

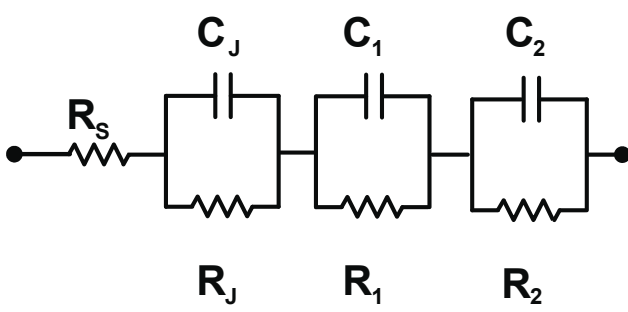

(b)

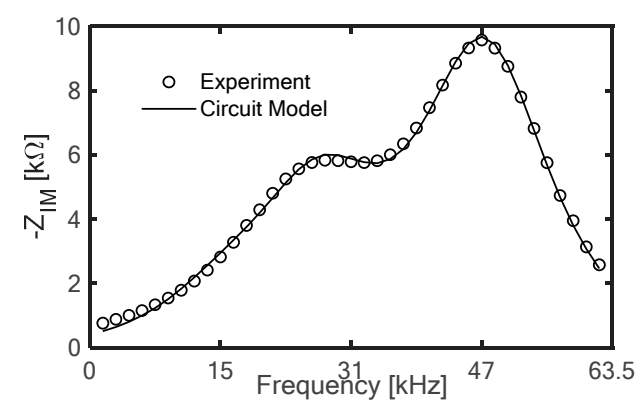

(d)

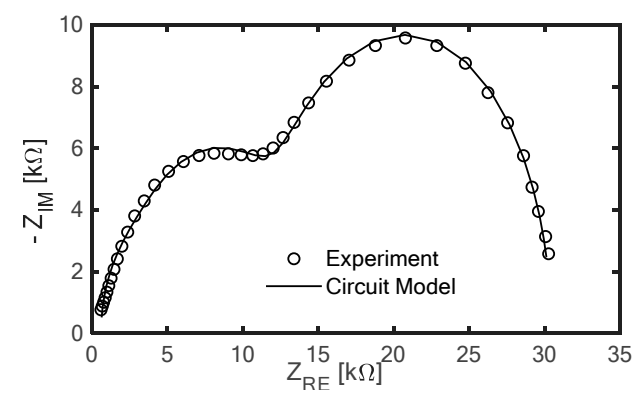

(e)

Figure 2. Au/G/Si/Al solar cell (a) Nyquist plot. (b) Equivalent circuit extracted from the data of Figure 2a. (c) Comparison in frequency between the real part of the impedance obtained from the circuit model extracted and the experiment data, for a DC bias of $0.1 \mathrm{~V}$. (d) Comparison in frequency between the imaginary part of the impedance obtained from the circuit model extracted and the experiment data, for a DC bias of $0.1 \mathrm{~V}$. (e) Nyquist plot comparison between the impedance obtained from the circuit model extracted and the experiment data, for a DC bias of $0.1 \mathrm{~V}$.

Adopting an automated procedure [16], the equivalent circuit configuration of Figure $2 b$ was extracted from the experimental data of Figure 2a. The mentioned procedure extracts the circuit configuration with the minimum number of RC pairs giving total impedance that provides the minimum relative error compared to the experimental impedance for each frequency and for all the available DC values. It should be observed that some contributions are bias dependent, such as the 
depletion capacitance, while this is not the case for others. This is the reason why the procedure identifies the circuit configuration by taking into account all available DC biases. The dependence on DC bias of the depletion capacitance is of formerly importance for the extraction of characterizing parameters of the junction. The adopted procedure works, at the same time, on the real part, $\mathrm{Z}_{\mathrm{RE}}$, and the imaginary part, $Z_{\mathrm{IM}}$, of the measured impedance, so that, the extracted circuit configuration gives the best results for both $Z_{\mathrm{RE}}$ and $\mathrm{Z}_{\mathrm{IM}}$. As an example, in Figure $2 \mathrm{c}, \mathrm{d}$, the Nyquist plots achieved by means of the above-mentioned circuit representation are compared with the experiments corresponding to the DC bias of $0.1 \mathrm{~V}$.

As we can see, there is an almost perfect overlap between experiments and model, for both real and imaginary part of the impedance. This means that the circuit configuration extracted from the automated procedure, which contains 4 lumped resistance and 3 lumped capacitors, is suitable to model the impedance in the whole frequency range and for all considered DC biases. The complete Nyquist plot achieved by composing the real and imaginary parts, compared with the experiments, is reported on Figure 2e.

Equally good results were achieved in the whole range of DC biases. The lumped parameters, resistances and capacitances, making the circuit model suitable in the complete bias range, are shown in Figure 3a,b, respectively. The values of such parameters, along with the corresponding circuit model, allow to quantify the role of each interface in the overall behaviour. Indeed, with reference to Figure 3a, $C_{j}$ can be attributed to the graphene-silicon interface; in fact, for negative bias, the typical dependence on the width of the depletion region can be recognized, while, for positive bias, the decreasing of $C_{j}$ can be attributed to carrier injection phenomena. The other two capacitances, $\mathrm{C}_{\mathrm{Au}}$ and $\mathrm{C}_{\mathrm{Al}}$, model the gold-graphene interface and the aluminium-silicon interface. In principle, these two capacitances cannot be distinguished each other, however, in this work, it is proposed that the highest is ascribable to the gold-graphene interface. This assumption is confirmed by looking at the behaviour of the corresponding resistance values, $R_{A u}$ and $R_{A l}$. More in detail, the decreasing of $R_{A u}$ and $R_{j}$ for positive $\mathrm{DC}$ bias is coherent with the nature of the junction. In fact, they are differential resistances and they start decreasing if the junction is injecting carriers. Conversely, $\mathrm{R}_{\mathrm{Al}}$ slightly increases when the $\mathrm{DC}$ bias is positive because the aluminium-silicon junction is reversed biased.

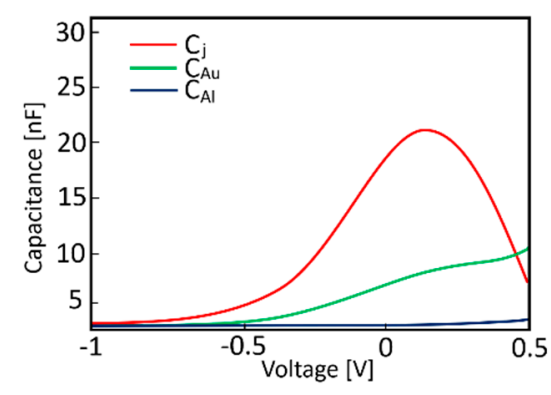

(a)

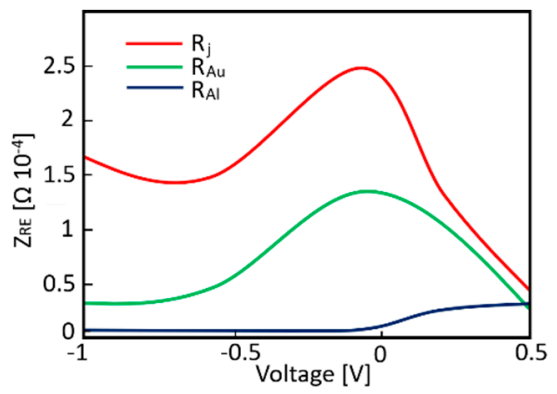

(b)

Figure 3. (a) Extracted lumped capacitances values. The depletion capacitance, $C_{j}$, is dominant, while the $C_{\mathrm{Au}}$ and $\mathrm{C}_{\mathrm{Al}}$ are associated to the interface between gold and graphene in one case or aluminium and silicon in the other. (b) Extracted lumped resistances values. The resistance associated to the graphene-silicon junction is $R_{j}$, while the $R_{A u}$ and $R_{A l}$ are associated to the interface between gold and graphene in one case or aluminium and silicon in the other.

The same analysis was performed on the solar cell with the graphitic glue contact (Graphite/G/Si/Al). The Nyquist plots are presented in Figure $4 \mathrm{a}$. As can be seen, the Nyquist plots are almost semicircular. This fact is a strong indication that less active interfaces are not playing an important role in this device. This assumption is corroborated by the circuit extraction procedure: indeed, only one capacitance dominates the behaviour of the solar cell, with only a marginal contribution of the aluminium-silicon 
interface. Therefore, the graphite-graphene interface does not behave as a parasitic junction, as is the case of the gold-graphene interface.

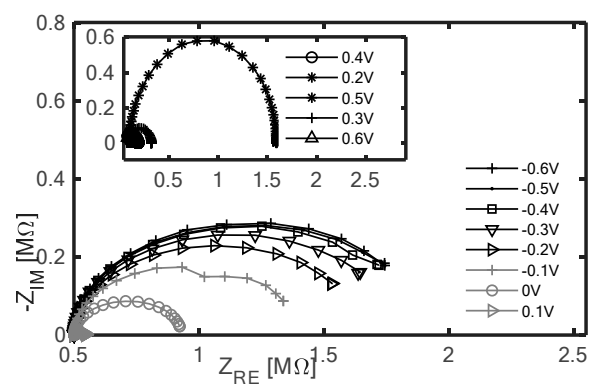

(a)

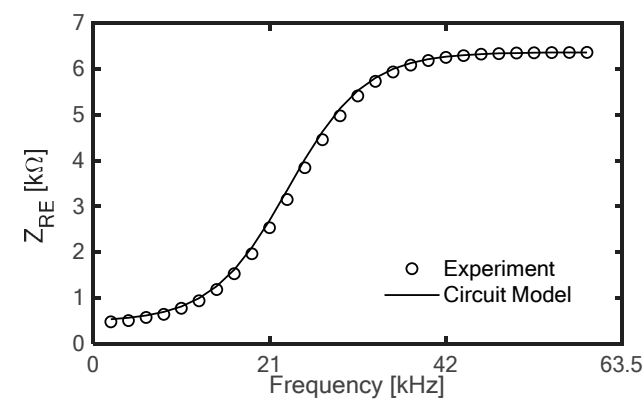

(c)

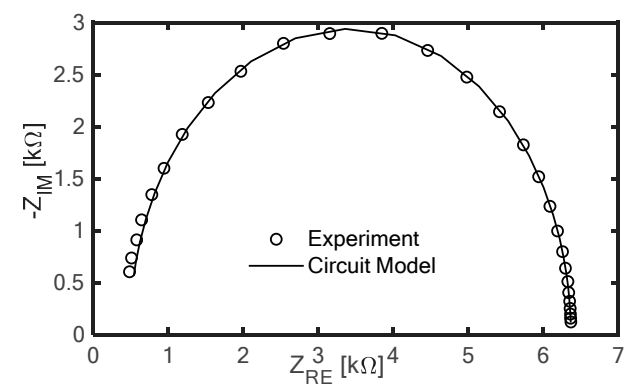

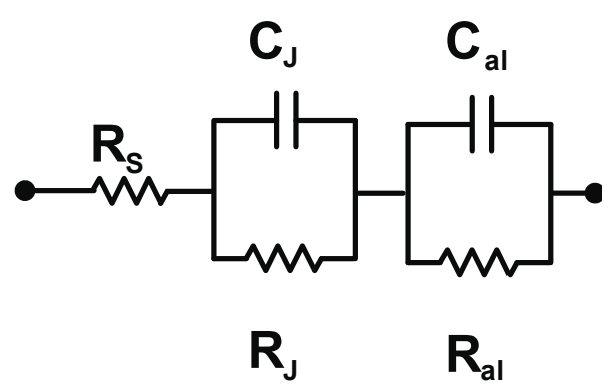

(b)

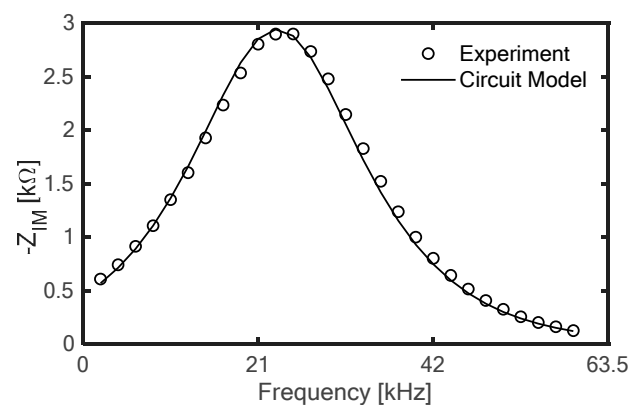

(d)

(e)

Figure 4. Graphite/G/Si/Al solar cell (a) Nyquist plot comparison between the impedance obtained from the circuit model extracted and the experiment data, for a DC bias of 0.1 V. (b) Equivalent circuit configuration. (c) Comparison of the real part of the impedance obtained from the experiment and from the circuit model, for DC bias equal to $0.2 \mathrm{~V}$. (d) Comparison of the imaginary part of the impedance obtained from the experiment and from the circuit model, for DC bias equal to $0.2 \mathrm{~V}$. (e) Nyquist plots comparison, for DC bias equal to $0.2 \mathrm{~V}$.

In Figure $4 b$, the extracted circuit configuration for the solar cell with the proposed front contact is shown. Only two lumped capacitances and three resistances are needed to describe the behaviour of the solar cell with graphitic front contact. The comparison of the modelled real and imaginary part of the impedance with the experiments are shown in Figure 4c,d (DC bias equal to $0.2 \mathrm{~V}$ ). The complete Nyquist plots are reported in Figure 4e.

Adopting the extraction procedure, the junction capacitance has been distinguished from the other contribution of the total impedance. The availability of the junction capacitance (different from the overall capacitance measurable at the terminals) made it possible to build the capacitance vs voltage $(\mathrm{C}-\mathrm{V})$ plot for each given frequency, as reported in Figure 5. Junction capacitance is varying with 
applied voltage, as in Figure 5, but also with frequency, as in the same figure. The variation of the junction capacitance with frequency is due to the different behaviour of existing traps/impurity with frequency. Traps can follow slow frequency signals while it is not the case for high frequency.

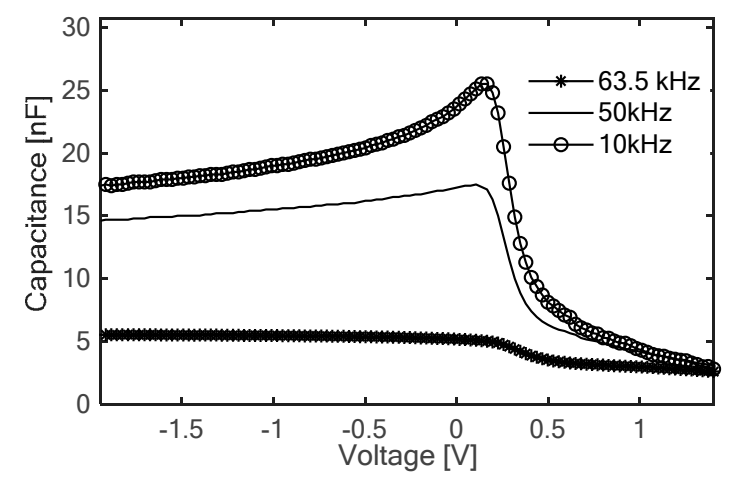

Figure 5. C-V plots of the Schottky junction capacitance for the solar cell with graphitic contact.

As it is known, curves like these allow for the evaluation of the built-in voltage, $\mathrm{V}_{\mathrm{bi}}$, by exploiting the following formula [17]:

$$
\frac{1}{C^{2}}=\frac{2}{\left(q \varepsilon_{S} N_{D}\right)}\left(V_{b i}-V\right)
$$

The plot of $1 / \mathrm{C}^{2}$ versus the voltage is reported in Figure 6, for the $\mathrm{C}-\mathrm{V}$ curve taken at a frequency $f=10 \mathrm{kHz}$. It is easy to recognize that the intercept with the $\mathbf{x}$ axis is $\mathrm{V}_{\mathrm{bi}}$. From the built-in voltage, the barrier height can be evaluated as well [17]:

$$
\phi_{B}=V_{b i}+\frac{k T}{q} \ln \left(\frac{N_{C}}{N_{D}}\right)
$$

where $\mathrm{N}_{\mathrm{D}}=5 \cdot 10^{15} \mathrm{~cm}^{-3}$ is the silicon doping concentration, and $\mathrm{N}_{C}$ is the equivalent density of states. By summing the barrier height derived from measurements, $\phi_{\text {Bmeas }}$, and the electron affinity of the silicon $(4.1 \mathrm{eV})$, the work function, $\mathrm{W}_{\mathrm{F}}$, of the graphene has been obtained [14,18]. Numerical values are reported in Figure 6.

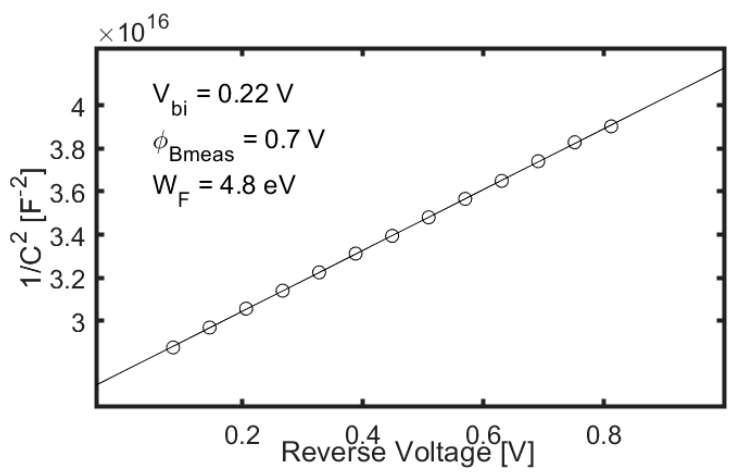

Figure 6. $1 / \mathrm{C}^{2}$ versus $\mathrm{V}$ plot. Dots represents experimental values, while the straight line is the interpolating line.

\section{Electrical Performance and External Quantum Efficiency Curves}

The electrical performance of both the solar cells with graphitic and gold front contacts has also been compared. The I-V curves under dark and light conditions of $\mathrm{Au} / \mathrm{G} / \mathrm{Si} / \mathrm{Al}$ and Graphite/G/Si/Al solar cells are shown respectively in Figure 7a,b. The comparison stresses the higher electric performance of the solar cells with graphitic contacts. This behaviour is also confirmed by the external quantum 
efficiency (EQE) curves in Figure 8, where a little improvement in the carriers collection can be seen for the graphitic contacts solar cell.

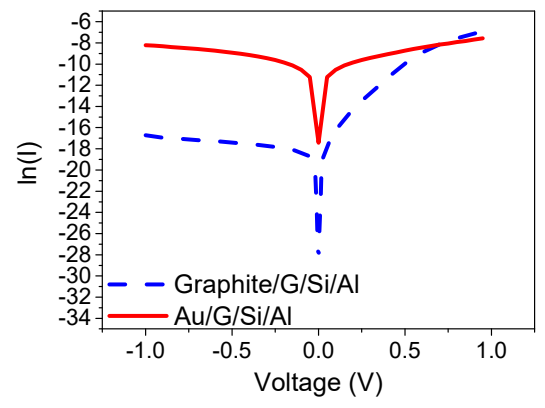

(a)

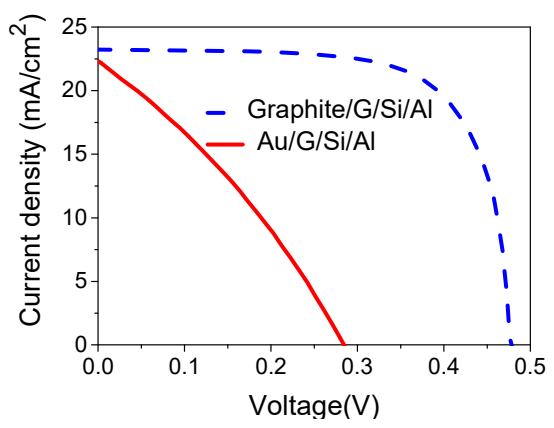

(b)

Figure 7. (a) Dark I-V curves of solar cell with graphitic contacts (dashed line) and gold contacts (straight line). (b) Light current density versus voltage $(\mathrm{J}-\mathrm{V})$ curves of graphitic contacts solar cell (dashed line) and gold contacts solar cell (straight line).

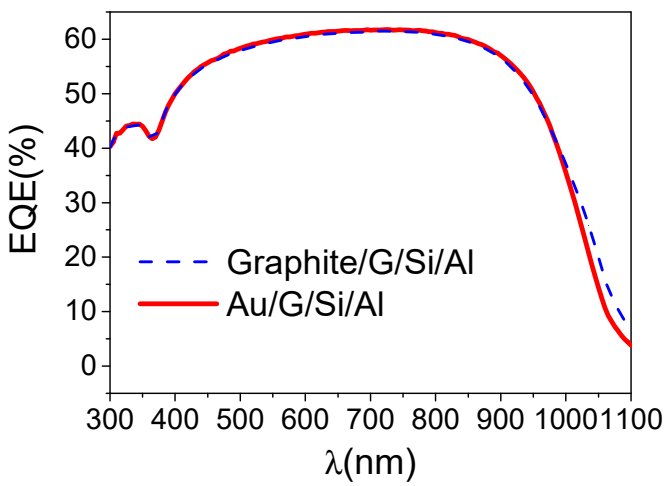

Figure 8. External quantum efficiency curves comparison of the solar cells with graphitic contact (dashed line) and gold contacts (straight line).

\section{Conclusions}

In this work, graphene-based solar cells have been studied and characterized using impedance spectroscopy. Adopting an automated procedure, it was possible to extract, from experimental Nyquist plots, the equivalent circuit configuration which is suitable for describing the solar cell behaviour. Extracted parameters gave a clear insight into the graphene-silicon interface and contact properties. In the specific case, it was evidenced that the contact technology based on the graphitic glue allows better performance than the standard gold contact technology. Moreover, the availability of the sole graphene-silicon interface capacitance allowed for the reliable extraction of both the work function of the graphene and the barrier height forming with silicon. The electrical properties of two different types of solar cells have also been compared, highlighting the superior performance of Graphite/G/Si/Al solar cell.

Author Contributions: Data curation, I.M.; Formal analysis, I.M., L.L. and P.G.; Funding acquisition, P.D.V.; Investigation, I.M., L.L. and P.G.; Resources, N.L.; Software, I.M.; Supervision, S.D. All authors have read and agreed to the published version of the manuscript.

Funding: This research received no external funding.

Acknowledgments: This work was supported by the Italian Ministry of Economic Development in the framework of the Operating Agreement with ENEA for Research on the Electric System.

Conflicts of Interest: The authors declare no conflicts of interest. 


\section{References}

1. Li, X.; Zhu, H.; Wang, K.; Cao, A.; Wei, J.; Li, C.; Jia, Y.; Li, Z.; Wu, D. Graphene-on silicon Schottky junction solar cells. Adv. Mater. 2010, 22, 2743-2748. [CrossRef] [PubMed]

2. Luongo, G.; Giubileo, F.; Genovese, L.; Iemmo, L.; Martucciello, N.; di Bartolomeo, A. I-V and C-V Characterization of a High Responsivity Graphene/Silicon Photodiode with Embedded MOS Capacitor. Nanomaterials 2017, 7, 158. [CrossRef] [PubMed]

3. Alialy, S.; Tecimer, H.; Uslu, H.; Altindal, S. A comparative Study on Electrical Characteristics of Au/N-Si Schottky Diodes, with and without Bi-Doped PVA Interfacial Layer in Dark and under Illumination at Room Temperature. Nanomed. Nanotechnol. 2013, 4, 3. [CrossRef]

4. Daliento, S.; Lancellotti, L. 3D Analysis of the performance degradation caused by series resistance in concentrator solar cells. Sol. Energy 2010, 84, 44-50. [CrossRef]

5. Bellone, S.; Licciardo, G.D.; Daliento, S.; Mele, L. Experimental measurements of majority and minority carrier lifetime profile in Si epilayers by the use of an improved OCVD method. IEEE Electron Devices Lett. 2005, 26, 501-503. [CrossRef]

6. Daliento, S.; Tari, O.; Lancellotti, L. Closed Form Analytical Expression for the Conductive and Dissipative Parameters of the MOS-C equivalent Circuit. IEEE Trans. Electron Devices 2010, 58, 3643-3646. [CrossRef]

7. Ershov, M.; Liu, H.C.; Li, L.; Buchanan, M.; Wasilewski, Z.R.; Jonscher, A.K. Negative capacitance effect in semiconductor devices. IEEE Trans. Electron Devices 1998, 45, 2196-2206. [CrossRef]

8. Bisquert, J.; Bertoluzzi, L.; Mora-Serao, I.; Garcia-Belmonte, G. Theory of Impedance and Capacitance Spectroscopy of Solar Cells with Dielectric Relaxation, Drift Diffusion Transport, and Recombination. J. Phys. Chem. 2014, 118, 18983-18991. [CrossRef]

9. Yadav, P.; Pandey, K.; Bhatt, V.; Kumar, M.; Kim, J. Critical aspects of impedance spectroscopy in silicon solar cell characterization: A review. Renew. Sustain. Energy Rev. 2017, 76, 1562-1578. [CrossRef]

10. Brana, A.F.; Fornies, E.; Lopez, N.; Garcia, B.J. High Efficiency Si Solar Cells Characterization Using Impedance Spectroscopy Analysis. J. Phys. 2015, 647, 012069.

11. Capasso, A.; Salamandra, L.; Faggio, G.; Dikonimos, T.; Buonocore, F.; Morandi, V.; Ortolani, L.; Lisi, N. Chemical Vapor Deposited Graphene-Based Derivative as High-Performance Hole Transport Material for Organic Photovoltaics. ACS Appl. Mater. Interfaces 2016, 8, 23844. [CrossRef] [PubMed]

12. Lancellotti, L.; Bobeico, E.; Castaldo, A.; DelliVeneri, P.; Lago, E.; Lisi, N. Effects of different graphene dopants on double antireflection coatings/graphene/n-silicon heterojunction solar cells. Thin Solid Films 2018, 646, 21-27. [CrossRef]

13. Capasso, A.L.; de Francesco, M.; Leoni, E.; Dikonimos, T.; Buonocore, F.; Lancellotti, L.; Bobeico, E.; Sarto, M.S.; Tamburrano, A.; Lisi, N.; et al. Cyclododecane as support material for clean and facile transfer of large-area few-layer graphene. Appl. Phys. Lett. 2014, 105, 113101. [CrossRef]

14. Lancellotti, L.; Bobeico, E.; della Noce, M.; Veneri, P.D.; Matacena, I. Work Function Determination of Transparent Contact for a: Si/c-Si Heterojunction Solar Cells. In Proceedings of the 2018 IEEE International Conference on Environment and Electrical Engineering and 2018 IEEE Industrial and Commercial Power Systems Europe (EEEIC/I\&CPS Europe) IEEE, Palermo, Italy, 12-15 June 2018; pp. 1-5.

15. Lancellotti, L.; Bobeico, E.; Castaldo, A.; DelliVeneri, P.; Lago, E.; Lisi, N. Doping of multilayer graphene for silicon based solar cells. In Proceedings of the 6th International Conference on Clean Electrical Power (ICCEP), Liguria, Italy, 27-29 June 2017; pp. 509-512.

16. Matacena, I. Equivalent circuit extraction procedure from Nyquist plots for graphene-silicon solar cells. In Proceedings of the 2019 15th Conference on Ph. D Research in Microelectronics and Electronics (PRIME), Lausanne, Switzerland, 15-18 July 2019; IEEE: Piscataway, NJ, USA, 2019.

17. Schroder, D.K. Semiconductor Material and Device Characterization; John Wiley \& Sons: New York, NY, USA, 2015.

18. Gnisci, A.; Faggio, G.; Lancellotti, L.; Messina, G.; Carotenuto, R.; Bobeico, E.; DelliVeneri, P.; Capasso, A.; Dikonimos, T.; Lisi, N. The Role of Graphene-Based Derivative as Interfacial Layer in Graphene/n-Si Schottky Barrier Solar Cells Physica Status Solidi (A). Appl. Mater. Sci. 2019, 216, 1800555.

(C) 2020 by the authors. Licensee MDPI, Basel, Switzerland. This article is an open access article distributed under the terms and conditions of the Creative Commons Attribution (CC BY) license (http://creativecommons.org/licenses/by/4.0/). 